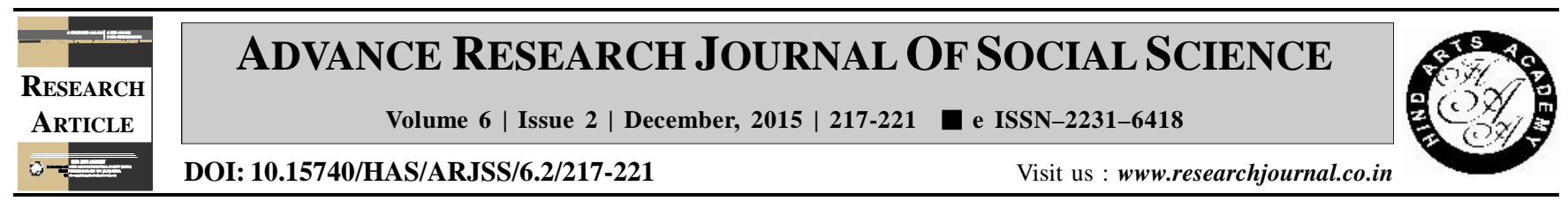

\title{
Impact of training on infant care practices for imparting knowledge to rural women
}

Anuradha Ranjan Kumari* and Laxmikant ${ }^{1}$

Krishi Vigyan Kendra (IIVR), Malhana, DEORIA(U.P.) INDIA

(Email : anuradha_rau@ rediffmail.com)

${ }^{1}$ Krishi Vigyan Kendra (SVPUA\&T), RAMPUR (U.P.) INDIA

\section{ARTICLE INFO :}

$\begin{array}{lll}\text { Received } & : & 13.10 .2015 \\ \text { Revised } & : & 07.11 .2015 \\ \text { Accepted } & : & 15.11 .2015\end{array}$

KEY WORDS :

Impact, Training, Infant care practices, Knowledge, Rural women

\section{HOW TO CITE THIS ARTICLE :}

Kumari, Anuradha Ranjan and Laxmikant (2015). Impact of training on infant care practices for imparting knowledge to rural women. Adv. Res. J. Soc. Sci., 6 (2) : 217221.

*Author for correspondence

\begin{abstract}
Platitude rate of decline in neonatal mortality rate is one of the major obstacles in achieving Millennium Development Goal 4 especially in developing countries. Even in India, nationwide interventions targeting safe mother and newborn care have not yielded the desired impact, indicating the necessity to combat neonatal mortality rate at population specific level. The present study was an attempt to develop and assess the effectiveness of training package on infant care practices for imparting knowledge to rural women as they have lack of knowledge and awareness about proper infant care practices and follow traditional practices. The study was conducted in Deoria district of U.P. pre and post test research design was used for present study. The study was done in two phase. In first phase training package consisting of variety of visual aids like leaflet, flash cards, modal, infant's clothes and chart were developed on different aspects of infant care practices along with literature. In second phase development training package was implement to selected respondents data were collected through interview method knowledge of respondents was assess in three steps pre test, exposure and post test the findings of the study revealed that after exposure of training package, the net gain in knowledge was highest in aspect of infant bathing and lower in infant health significant improvement in the knowledge was found as a result of exposure of training package as the pre test score was increased 47.81 to 81.45 per cent with the gain in knowledge of about 33.64 per cent.
\end{abstract}

